\title{
Myocardial infarction in an adult with cystic fibrosis and heart and lung transplant
}

\author{
James Eaden ${ }^{*}$ and Daniel Peckham
}

\begin{abstract}
We present a case of myocardial infarction in a 19 year old female with cystic fibrosis who had a heart and lung transplant performed at the age of four years old. She presented atypically with a one day history of severe, intermittent, central, sharp chest pain, radiating to her back and down her left arm. A coronary angiogram showed proximal stenosis of the left anterior descending artery and right coronary artery. She was treated with percutaneous coronary intervention, involving drug eluting stents to the left anterior descending artery (LAD) and the right coronary artery (RCA). In this study we discuss the pathophysiology, investigations and treatment of cardiac transplant vasculopathy. Although complete reversal of LAD and RCA stenosis was achieved, routine followup with coronary angiography and careful control of cardiac risk factors will be important to identify and reduce future restenosis and adverse cardiac events.
\end{abstract}

Keywords: Cardiac transplant vasculopathy, Cystic fibrosis, Heart and lung transplant, Myocardial infarction

\section{Background}

Heart and lung transplantation in children with cystic fibrosis (CF) and end-stage lung disease are now rarely performed, with bilateral sequential lung transplantation (BSLT) being the preferred procedure [1]. Although rare, myocardial infarction (MI) in the perioperative period following BSLT has been reported in patients with CF [2-4]. However, to our knowledge there are no reports of a MI occurring years after a heart and lung transplantation in a patient with CF. We present a case of MI in a 19 year old female with CF who had a heart and lung transplant performed at the age of four years old.

\section{Case presentation}

A 19 year old female with CF who had a heart and lung transplantation in 1997 presented to the Emergency Department (ED) with a one day history of severe, intermittent, central, sharp chest pain, radiating to her back and down her left arm. This was associated with intermittent paraesthesia, pallor and coldness in her left hand. The chest pain was worse on deep inspiration but was not positional or exacerbated by movement. Over the

\footnotetext{
* Correspondence: jameseaden@doctors.org.uk

Leeds Cystic Fibrosis Unit, St James's University Hospital, Beckett Street, Leeds, West Yorkshire LS9 7TF, UK
}

previous four weeks she had been having a productive cough with a reduced exercise tolerance but no chest pain.

On examination there was no swelling, pallor or erythema of her left arm/hand and no chest wall tenderness. She was well perfused with a regular pulse and a stable blood pressure. No murmur or added heart sound was present and vesicular breath sounds were heard on auscultation. A chest radiograph showed no acute changes and an initial electrocardiogram (ECG) taken in the ED showed a sinus tachycardia with no ST or T wave changes. Initial blood tests were normal apart from an elevated white cell count $\left(13.64 \times 10^{9} / \mathrm{L}\right)$, creatinine $(138 \mu \mathrm{mol} / \mathrm{L})$ and urea $(12.8 \mu \mathrm{mol} / \mathrm{L})$.

The patient was admitted from the ED to the CF ward where she had a repeat ECG and a troponin I blood test after being assessed by a junior doctor. The repeat ECG showed sinus tachycardia with $\mathrm{T}$ wave inversion in leads I, aVL, V2-V4, but no ST changes or Q waves. The troponin I level (taken approximately 30 hours after the onset of chest pain) was 10,801. A computed tomography pulmonary angiogram (CTPA) the following day showed no pulmonary embolus (PE) and no vascular abnormalities. A coronary multi-slice computed tomography (MSCT) was not performed as it is not used as an 
investigation of acute MI in inpatients at St James's University Hospital.

Later that day the patient was reviewed by a cardiology registrar who performed a bedside echocardiogram. This demonstrated moderate left ventricular impairment due to extensive apical akinesis and anterior/antero-septal hypokinesis with an ejection fraction of $42 \%$. No valvular dysfunction was identified. That evening the patient received percutaneous coronary intervention (PCI) which illustrated a 95\% proximal stenosis of the left anterior descending artery (LAD), normal left circumflex artery (LCx) and 80-95\% proximal stenosis of the right coronary artery (RCA) (Figure 1). Drug eluting stents (DES) were inserted into the LAD and RCA and a complete reversal of the stenosis was achieved. The time between the onset of chest pain and PCI (pain-to-needle time) was approximately 60 hours. This delay in treatment was due to the atypical nature of the chest pain as well as late presentation to the ED. The patient was started on aspirin, bisoprolol, ramipril, lansoprazole and 12 months of ticagrelor and was discharged from hospital five days later.

\section{Discussion}

Cardiac transplant vasculopathy (CTV) is a rapidly progressive form of atherosclerosis involving thickening of

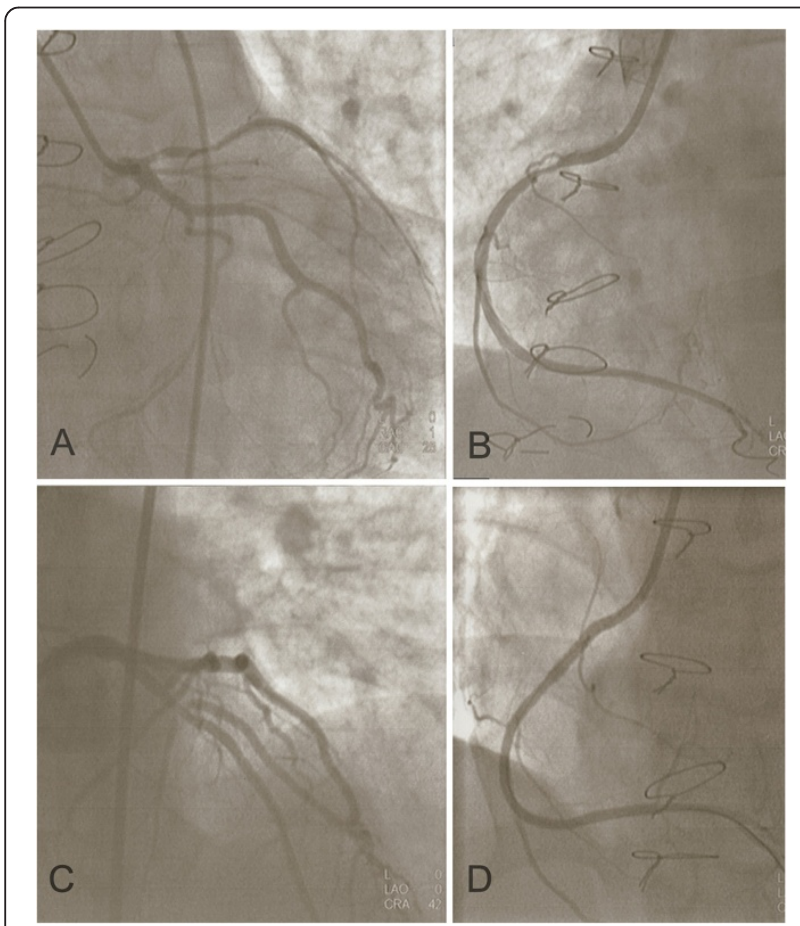

Figure 1 Angiogram images. 95\% proximal stenosis of LAD (A), 80-95\% proximal stenosis of RCA (B), post-stenting of LAD (C), poststenting of RCA (D). the intima, leading to stenosis of coronary artery grafts and subsequent myocardial ischaemia [5]. It is generally a diffuse process that occurs early after transplantation. However, years after transplantation there can be focal atherosclerotic stenosis, diffuse intimal thickening or a combination of both [6]. CTV is a significant complication as it is the leading cause of death in patients with a heart transplant [7].

The development of CTV is thought to be due to a combination of an immune-mediated process and nonimmunologic risk factors resulting in endothelial injury and subsequent fibroelastic proliferation of the intima [6]. Risk factors for CTV can be separated into traditional risk factors (hypertension, hyperlipidaemia and diabetes mellitus) and transplant associated risk factors (donor factors, cytomegalovirus (CMV), HLA mismatch and number of rejection episodes) [8]. The patient in this case study did not have diabetes mellitus or hypertension. There was no family history of premature ischaemic heart disease. She was not obese, did not smoke and there was no history of drug abuse. There were no concerns regarding her adherence to medication. She had been taking pravastatin for at least five years and in May 2012 she had a total cholesterol level of $3.5 \mathrm{mmol} / \mathrm{L}$ and a triglyceride level of $1.4 \mathrm{mmol} / \mathrm{L}$. There was no evidence of CMV infection, HLA mismatch or rejection and the details of the donor are unknown.

The diagnosis of CTV is particularly challenging as it rarely presents with typical angina, despite $10-30 \%$ of patients with heart transplants having partial reinnervation [6]. However, as demonstrated in this case report, CTV can present with atypical chest pain. Many patients with CTV seek medical attention with symptoms of congestive heart failure (e.g. reduced exercise tolerance, dyspnoea on exertion and orthopnoea) and will subsequently have impaired systolic function [6]. Others may present with ventricular arrhythmias or sudden cardiac death [9] and therefore early diagnosis of CTV is important.

In many transplant centres, patients with heart transplants receive annual coronary angiography. However, due to the diffuse nature of CTV, angiography may underestimate the severity of disease or miss it completely [8]. The patient in this case study had a coronary angiogram in 2003 and 2005 which were both normal.

The gold standard investigation of CTV is intravascular ultrasound (IVUS) which has the ability to assess the amount of intimal thickness and identify vessel wall morphology [8]. A study by Mehra et al. [10] involving 74 patients with a heart transplant showed that despite having a normal coronary angiogram, the presence of intimal thickness of more than $0.5 \mathrm{~mm}$ on IVUS was associated with more adverse cardiovascular events (death, MI and retransplantation) after approximately four years follow-up. A similar study by Rickenbacher et al. [11] 
involving 145 patients (one to ten years after heart transplantation) demonstrated a significantly increased fouryear overall mortality in patients with a mean intimal thickness of more than $0.3 \mathrm{~mm}$ on IVUS compared to those with a mean intimal thickness of $0.3 \mathrm{~mm}$ or less. Using serial IVUS Tsutsui et al. [12] found that the majority of intimal thickening occurs within the first year following heart transplantation.

A number of non-invasive radiological modalities (e.g. dobutamine stress echocardiography (DSE), myocardial perfusion imaging (MPI) and multislice computed tomography (CT) coronary angiography) have also been utilized to assist in the diagnosis of CTV, with variable degrees of sensitivity and specificity [8]. A pilot study by Usta et al. [13] involving 10 asymptomatic patients with heart transplants showed that multi-slice spiral $\mathrm{CT}$ was equal to coronary angiography in detecting CTV in epimyocardial vessel segments. Multi-slice spiral CT was also more cost-effective with fewer complications when compared with coronary angiography, making it a useful alternative. A study by Spes et al. [14] comparing DSE with coronary angiography and IVUS in 109 patients with heart transplants found that DSE had a sensitivity of $72 \%$. The authors suggested that DSE has a similar prognostic value as IVUS and coronary angiography and that a normal DSE can justify postponing more invasive investigations [14].

The most effective treatment of CTV is prevention and modification of risk factors using antihypertensive agents (e.g. ACE inhibitors and calcium channel blockers), statins (e.g. pravastatin) and strict diabetic control. Coronary artery bypass grafting is rarely an option in CTV due to the diffuse nature of the disease process and the limited availability of donor hearts makes re-transplantation unlikely. In patients with heart transplants presenting with chest pain (atypical or angina) or features of congestive heart failure, if the ECG or echocardiogram show ischaemic changes or wall motion abnormalities, acute coronary syndrome should be suspected and patients should be treated accordingly with antiplatelet agents and PCI [6].

A systematic review of six small, retrospective, nonrandomised studies comparing the use of bare-metal stents (BMS) with drug-eluting stents (DES) in the treatment of CTV (328 lesions treated with BMS and 287 lesions treated with DES) showed that DES were associated with a lower restenosis rate at 6-12 months, but in only half of the six studies were the differences statistically significant [15]. There was no difference in major adverse cardiac events between DES and BMS, but the studies were underpowered and there was considerable variation among the six studies in terms of length of follow-up, type of DES used and the reason for PCI [15]. Less than $20 \%$ of the coronary angiograms were performed for possible acute coronary syndromes or stable angina with the main indication being to screen for CTV [15].

A recent retrospective nonrandomised study involving 34 patients receiving a total of 46 stents (27 DES vs 19 BMS) is the first to suggest a clinical benefit (reduced rates of nonfatal MI and cardiac death) with DES compared to BMS in the treatment of CTV [16]. Randomised controlled trials are required to confirm the superiority of DES over BES in the treatment of CTV especially in improving survival or reducing major adverse cardiac events [17].

Maintenance immunosuppression following heart transplantation usually consists of a triple therapy of corticosteroids (usually prednisolone), a calcineurin inhibitor (CNI) (cyclosporine or tacrolimus) and an antiproliferative agent [18]. Azathioprine was the first antiproliferative agent used post heart transplantation; however this has now largely been replaced by mycophenolate mofetil or newer agents such as sirolimus and everolimus. A study involving 273 heart transplant recipients found mycophenolate mofetil to be significantly superior to azathioprine at preventing CTV after five years, when combined with either tacrolimus or cyclosporine [19]. In a randomised, multicentre study involving 634 heart transplant recipients, everolimus was shown to have greater efficacy in reducing the severity and incidence of CTV after one year compared to azathioprine [20]. Sirolimus has also been shown to reduce the progression of CTV either in combination with a CNI [21] or as primary immunosuppression [22,23]. However, the efficacy of everolimus and sirolimus against the progression of CTV in the long-term waits to be seen.

Tacrolimus and cyclosporine have failed to demonstrate prevention of CTV after heart transplantation and there appears to be little difference between these CNIs in terms of long-term development of CTV [24]. However, tacrolimus has been shown to be associated with a lower incidence of hyperlipidaemia and hypertension with no difference in hyperglycaemia, renal function or incidence of infection when compared to cyclosporine [25]. It has also been suggested that tacrolimus monotherapy in heart transplant recipients is safe and efficacious and is not associated with increased high-grade rejection or CTV $[26,27]$.

In terms of CTV prevention, the optimum maintenance immunosupression regime is unclear and a longterm randomised trial is required to determine this. The maintenance immunosupression regime following heart and lung transplantation for the patient in this case consisted of tacrolimus and prednisolone without the use of an antiproliferative agent. There was no change in the maintenance immunosupression regime post MI. 


\section{Conclusion}

MI must be considered in young patients with CF and a heart and lung transplant with atypical chest pain. Although complete reversal of LAD and RCA stenosis was achieved in this case with the use of PCI and DES, routine follow-up with coronary angiography and careful control of cardiac risk factors will be important to identify and reduce future restenosis and adverse cardiac events.

\section{Consent}

Written informed consent was obtained from the patient for publication of this case report and any accompanying images.

\section{Abbreviations \\ BMS: Bare-metal stents; BSLT: Bilateral sequential lung transplantation; CF: Cystic fibrosis; CFRD: Cystic fibrosis related diabetes; CMV: Cytomegalovirus; CNI: Calcineurin inhibitor; CTV: Cardiac transplant vasculopathy; DES: Drug eluting stents; DSE: Dobutamine stress echocardiography; ECG: Electrocardiogram; ED: Emergency Department; CTPA: Computed tomography pulmonary angiogram; IVUS: Intravascular ultrasound; LAD: Left anterior descending artery; LCx: Left circumflex artery; Ml: Myocardial infarction; PCl: Percutaneous coronary intervention; PE: Pulmonary embolus; RCA: Right coronary artery; MPI: Myocardial perfusion imaging; CT: Computed tomography.}

\section{Competing interests}

The authors declare that they have no competing interests.

\section{Authors' contributions}

JE and DP were both involved in the management of the case. JE wrote the case report with assistance from DP. Both authors read and approved the final manuscript.

\section{Acknowledgements}

Thanks to Steven Conway for providing writing assistance.

Received: 21 December 2012 Accepted: 19 May 2013

Published: 7 June 2013

\section{References}

1. Burch M, Aurora P: Current status of paediatric heart, lung, and heartlung transplantation. Arch Dis Child 2004, 89:386-389.

2. Quattrucci S, Rolla M, Cimino G, Bertasi S, Cingolani S, Scalercio F, Venuta F, Midulla F: Lung transplantation for cystic fibrosis: 6-year follow-up. J Cyst Fibros 2005, 4:107-114.

3. Aratari MT, Venuta F, De Giacomo T, Rendina EA, Anile M, Diso D, Francioni F, Quattrucci S, Rolla M, Pugliese F, Liparulo V, Di Stasio M, Ricella C, Tsagkaropoulos S, Ferretti G, Coloni GF: Lung transplantation for cystic fibrosis: Ten years of experience. Transp/ Proc 2008, 40:2001-2002.

4. Coloni GF, Venuta F, Ciccone AM, Rendina EA, De Giacomo T, Filice MJ, Diso D, Anile M, Andreetti C, Aratari MT, Mercadante E, Moretti M, Ibrahim M: Lung transplantation for cystic fibrosis. Transpl Proc 2004, 36:648-650.

5. Mehra MR, Crespo-Leiro MG, Dipchand A, Ensminger SM, Hiemann NE, Kobashigawa JA, Madsen J, Parameshwar J, Starling RC, Uber PA: International society for heart and lung transplantation working formulation of a standardized nomenclature for cardiac allograft vasculopathy-2010. J Heart Lung Transplant 2010, 29:717-727.

6. Juan M, Aranda JR, Hill J: Cardiac transplant vasculopathy. Chest 2000, 118:1792-1800.

7. Garg R, Singh A, Aggarwal K: The role of multiple drug-eluting stents in the treatment of cardiac transplant vasculopathy. South Med J 2008, 101:1252-1254
8. Colvin-Adams M, Agnihotri A: Cardiac allograft vasculopathy: current knowledge and future direction. Clin Transplant 2011, 25:175-184.

9. Weis M, Von Scheidt W: Cardiac allograft vasculopathy: a review. Circulation 1997, 96:2069-2077.

10. Mehra MR, Ventura HO, Stapleton DD, Smart FW, Collins TC, Ramee SR: Presence of severe intimal thickening by intravascular ultrasonography predicts cardiac events in cardiac allograft vasculopathy. J Heart Lung Transplant 1995, 14:632-639.

11. Rickenbacher PR, Pinto FJ, Lewis NP, Hunt SA, Alderman EL, Schroeder JS, Stinson EB, Brown BW, Valantine HA: Prognostic importance of intimal thickness as measured by intracoronary ultrasound after cardiac transplantation. Circulation 1995, 92:3445-3452.

12. Tsutsui H, Ziada KM, Schoenhagen P, lyisoy A, Magyar WA, Crowe TD, Klingensmith JD, Vince DG, Rincon G, Hobbs RE, Yamagishi M, Nissen SE, Tuzcu EM: Lumen loss in transplant coronary artery disease is a biphasic process involving early intimal thickening and late constrictive remodelling. Circulation 2001, 104:653-657.

13. Usta E, Burgstahler C, Aebert H, Schroeder S, Helber U, Kopp AF, Ziemer G: The challenge to detect heart transplant rejection and transplant vasculopathy non-invasively - a pilot study. J Cardiothorac Surg 2009, 4:43.

14. Spes $\mathrm{CH}$, Klauss $V$, Mudra H, Schnaack SD, Tammen AR, Rieber J, Siebert U, Henneke K, Uberfuhr P, Reichart B, Theisen K, Angermann CE: Diagnostic and prognostic value of serial dobutamine stress echocardiography for noninvasive assessment of cardiac allograft vasculopathy: a comparison with coronary angiography and intravascular ultrasound. Circulation 1999, 100:509-515.

15. Dasari TW, Hennebry TA, Hanna EB, Saucedo JF: Drug eluting versus bare metal stents in cardiac allograft vasculopathy: A systematic review of literature. Catheter Cardiovasc Interv 2011, 77:962-969.

16. Tremmel JA, Ng MKC, Ikeno F, Hunt SA, Lee DP, Yeung AC, Fearon WF: Comparison of drug-eluting versus bare metal stents in cardiac allograft vasculopathy. Am J Cardiol 2011, 108:665-668.

17. Singh S, Khosla S, Gupta V: The role of drug-eluting stents in treating cardiac transplant vasculopathy. South Med J 2008, 101:1198-119.

18. Hunt SA, Haddad F: The changing face of heart transplantation. J Am Coll Cardiol 2008, 52:587-598.

19. Kaczmarek I, Ertl B, Schmauss D, Sadoni S, Knez A, Daebritz S, Meiser B, Reichart B: Preventing cardiac allograft vasculopathy: Long term beneficial effects of mycophenolate mofetil. J Heart Lung Transplant 2006, 25:550-556.

20. Eisen HJ, Tuzcu M, Dorent R, Kobashigawa J, Mancini D, Valantine-von Kaeppler HA, Starling RC, Sorensen K, Hummel M, Lind JM, Abeywickrama $\mathrm{KH}$, Bernhardt P: Everolimus for the prevention of allograft rejection and vasculopathy in cardiac-transplant recipients. N Engl J Med 2003, 349:847-858.

21. Mancini D, Pinney S, Burkhoff D, LaManca J, Itescu S, Burke E, Edwards N, Oz $M$, Marks AR: Use of rapamycin slows progression of cardiac transplantation vasculopathy. Circulation 2003, 108:48-53.

22. Topilsky $Y$, Hasin $T$, Raichlin E, Boilson BA, Schirger JA, Pereira NL, Edwards BS, Clavell AL, Rodeheffer RJ, Frantz RP, Maltais S, Park SJ, Daly RC, Lerman A, Kushwaha SS: Sirolimus as primary immunosuppression attenuates allograft vasculopathy with improved late survival and decreased cardiac events after cardiac transplantation. Circulation 2012, 125:708-720.

23. Raichlin E, Bae J, Khalpey Z, Edwards BS, Kremers WK, Clavell AL, Rodeheffer RJ, Frantz RP, Rihal C, Lerman A, Kushwaha SS: Conversion to sirolimus as primary immunosuppression attenuates the progression of allograft vasculopathy after cardiac transplantation. Circulation 2007, 116:2726-2733

24. Keogh A: Calcineurin inhibitors in heart transplantation. J Heart Lung Transplant 2004, 23:S202-S206.

25. Taylor DO, Barr ML, Radovancevic B, Renlund DG, Mentzer RM, Smart FW, Tolman DE, Frazier $\mathrm{OH}$, Young JB, VanVeldhuisen P: A randomized, multicenter comparison of tacrolimus and cyclosporine immunosuppressive regimens in cardiac transplantation: Decreased hyperlipidemia and hypertension with tacrolimus. J Heart Lung Transplant 1999, 18:336-345

26. Lubitz SA, Baran DA, Alwarshetty MM, Pinney S, Kaplan S, Chan M, Courtney MC, Lansman SL, Spielvogel D, Gass AL: Long-term results of tacrolimus 
monotherapy in cardiac transplant recipients. J Heart Lung Transplant 2006, 25:699-706.

27. Baran DA, Zucker MJ, Arroyo LH, Alwarshetty MM, Ramirez MR, Prendergast TW, Goldstein DJ, Camacho M, Gass AL, Carr C, Cohen M: Randomized trial of tacrolimus monotherapy: tacrolimus in combination, tacrolimus alone compared (the TICTAC trial). J Heart Lung Transplant 2007, 26:992-997.

doi:10.1186/2049-6958-8-37

Cite this article as: Eaden and Peckham: Myocardial infarction in an adult with cystic fibrosis and heart and lung transplant. Multidisciplinary Respiratory Medicine 2013 8:37.

\section{Submit your next manuscript to BioMed Central and take full advantage of:}

- Convenient online submission

- Thorough peer review

- No space constraints or color figure charges

- Immediate publication on acceptance

- Inclusion in PubMed, CAS, Scopus and Google Scholar

- Research which is freely available for redistribution 